\title{
A silver wave? Filipino shipmates' experience of merchant seafaring
}

\author{
Joanne McVeigh $^{\mathrm{a}, \mathrm{b}, *}$, Malcolm MacLachlan ${ }^{\mathrm{a}, \mathrm{b}, \mathrm{c}, \mathrm{d}}$ \\ a Department of Psychology, Maynooth University, Maynooth, Ireland \\ ${ }^{\mathrm{b}}$ Assisting Living \& Learning (ALL) Institute, Maynooth University, Maynooth, Ireland \\ ${ }^{\mathrm{c}}$ Centre for Rehabilitation Studies, Stellenbosch University, Cape Town, South Africa \\ d Olomouc University Social Health Institute, Palacký University, Olomouc, Czech Republic
}

\section{A R T I C L E IN F O}

\section{Keywords:}

Maritime

Merchant seafarers

Stress

Resilience

Well-being

Qualitative

\begin{abstract}
A B S T R A C T
Aims: Seafarers are an occupational group amongst those at the highest risk for stress, which may in turn influence their mental and physical health. The primary aim of this study was to explore perceptions and experiences of stress, resilience, and well-being amongst a sample of Filipino merchant seafarers.

Methods: Focus groups were conducted with merchant seafarers working in a large shipping organisation. Four focus groups were conducted, each with eight ratings $(n=32)$ (all male). Participants were Filipino ratings across all departments (deck, engine and galley), and worked onboard liquefied natural gas carriers, product oil tankers and crude oil tankers, operating globally. Qualitative data was analysed using the descriptive and interpretive qualitative methods.

Results: Ratings communicated their perceptions and experiences of stress, resilience and well-being in relation to 11 domains: workload; safety; social; support; salary; food; shore leave and signing off and on; nationality and culture; management; inequality; and optimisation. Two critical broader themes interlaced the findings. The first, recent changes, was highlighted by participants regarding the need for more socialisation and shore leave for example. The second, organisational justice, was emphasised by ratings regarding, for instance, the importance of an equal and fair work environment.

Conclusion: Supporting the psychosocial well-being of seafarers may benefit both the individual seafarer and their employer, through improved well-being and increased work performance, comprising a virtuous reinforcing cycle. Importantly, a work environment seen as supportive and just is necessary to provide a good platform upon which individually focused psychosocial interventions can be optimally applied.
\end{abstract}

\section{Introduction}

\subsection{The global outsourced seafarer}

"Sail on, seafarer, on the beautiful blue ocean, lifted up on a silver wave of self-worth, duty and shipmates' welcome."

[52]

Trade and development are underpinned by maritime transport, whereby over $80 \%$ of the volume and $70 \%$ of the value of global trade is transported by sea [73]. In 2015, the world merchant fleet was an estimated 68,723 ships, with a global supply of 1647,500 seafarers, and the largest seafarer supply countries being China, Philippines, Indonesia, Russian Federation and Ukraine [10].

Ship owners cost-save on crews from low- and middle-income countries (LMICs) to yield competitive rates [37]. Carter [20] suggests that seafarers from higher-income countries and from countries with strong anti-discrimination laws and social security support are being replaced, frequently due to the expenses for companies of payments to social funds and due to the legal risks from any ill-treatment of individuals. Carter [20, p. 187] further specifies that seafarers who are now recruited from lower-cost crewing countries "may be discriminated against and discharged at will, sometimes leaving their families and communities to pick up the costs of harm that has arisen while they are in the employment of a company with its base in a developed country where such actions would be outside the law".

It has been suggested that "discrimination according to nationality is endemic in the shipping industry" [37, p. 24]. Seafarers from LMICs such as the Philippines, with weaker economic power and economic positions in the international maritime labour market, generally have disadvantaged employment contracts and working conditions relative

\footnotetext{
* Correspondence to: Department of Psychology, Maynooth University, North Campus, Room SF12, John Hume Building, Maynooth, Co. Kildare, Ireland.

E-mail address: Joanne.McVeigh@mu.ie (J. McVeigh).
} 
to seafarers from higher-income countries $[47,6]$.

For example, seafarers from LMICs are usually at sea for longer average durations; exemplified by a typical contract for most Tuvaluans of 10-12 months [13]. Oldenburg et al. [59] conducted interviews with 134 seafarers sailing under German-flagged vessels, and found that Europeans reported significantly shorter durations onboard than nonEuropean seafarers (4.9 versus 9.9 months per year), while superior duties (i.e. duties as an officer onboard) were conducted by $63.2 \%$ of the Europeans versus $6.4 \%$ of the non-European seafarers. The researchers surmised that this "social gradient" was likely a substantial stress factor onboard.

Furthermore, seafarers' salaries can be based on those of their domestic country, rather than collective agreements or the minimum wage of the country managing the vessel [23]. As a result, discrimination and perceived inequity and unfairness in the maritime industry include different pay rates for the same job $[18,28,9]$. This dual salary system engenders a "socio-economic apartheid" ([15], p. 129). As asserted by Carr [16, p. 146], "deleterious effects from dual salaries on work motivation and turnover do not discriminate between sectors". Lower pay is symbolic of social dominance, lower respect, and lower value in the organisation [49].

Carter [18, p. 62] calls attention to these inequities by suggesting that: "Perceived inequity can contribute to distress. Common concerns are: hours worked, length of tour, the link of senior posts to nationality, different pay rates for the same job, age discrimination in recruitment, access to health care during employment and between contracts". Carter [18, p. 62] goes even further by arguing that: "Inequity may also be seen as a form of neo-colonialism with rich ship owning countries exploiting those with less economic strength".

In LMICs, communities may be significantly dependent on seafarers' income, in the midst of limited social protection [13]. As asserted by Bloor [11, p. 976]: "The outsourced global seafarer is prepared to work hard: labour power is limited, alternative employment opportunities in the new labour supply countries are few, and crew are frequently the sole support of extended families". The free market structure of the seafaring industry places considerable pressure on seafarers due to the risk of cheaper labour supplies, creating barriers to requesting higher wages and/or more favourable working conditions [37]. The concept of sweat ships denotes similar exploitation of employees [47,77]. Although strong seafarer unions are in place in several countries, they are frequently unwilling to address unfair and exploitative working conditions, so that they can protect seafarers from their own country from losing employment; recognising that there are always seafarers from other countries who are willing to work for the conditions offered [47].

\subsection{Keep calm and be a seafarer: Stress at sea and mental health}

Recent changes in the maritime industry have for the most part escalated rather than mitigated occupational stressors experienced at sea. Faster turnaround schedules in ports, increased use of technology, decreased manning, labour intensification, and social isolation have radically transformed the seafaring landscape $[2,28]$. As may be expected therefore, seafarers are an occupational group amongst those at the highest risk for stress [46], which may adversely impact on their mental health [42].

Psychological functioning including depression, anxiety, suicide, and alcohol or drug dependence are recognised health problems in the maritime industry [50]. Indeed, minor mental health problems are the most common type of ill-health on non-passenger ships [19]. Stressors such as months or years spent away from home, loneliness, harassment or bullying, long work hours without sufficient sleep, a lack of shore leave, and short turnaround schedules in ports, may result in anxiety and depression, and for some, suicide [40].

In 2015 , suicide accounted for $1.4 \%$ of all deaths globally [78]. However, suicide in the seafaring population may be substantially more prevalent [69]. Statistics of the U.K. Protection and Indemnity Club indicate that suicide was the cause of $4.4 \%$ of deaths onboard from 2014 to 2015 , and this figure escalated to $15.3 \%$ for the year 2015-2016 [75]. A recent review [55] reported that investigations of depression and suicide amongst seafarers indicate improvement, although numerous recent case series suggest that suicide is still problematic.

Awareness of mental health problems onboard is growing, and several initiatives are evident including the increased availability on ships and in docks of leaflets providing mental health information [50]. However, a great deal of interventions addressing depression and suicide are individualistic in focus and scope. Initiatives such as leaflets for stress reduction or a $24 / 7$ assistance hotline are focused at seafarers themselves, and are therefore only tertiary measures (addressing stress outcomes) or at times secondary measures of intervention (support with coping with stressors) [69]. While these initiatives are of great value in raising awareness and providing support for coping with stress, they do not focus on reducing the primary occupational stressors (primary causes) [69]. While depression, suicide, and other forms of psychological distress may be individually experienced, their origins are multifaceted and cannot be addressed only at the level of individual behaviour.

For example, organisational justice, which may be described as individuals' perceptions of fairness regarding an organisation's policies, pay systems and practices [32], is associated with mental health [57]. This implies that inequities experienced by seafarers from LMICs, including the the linking of nationality to senior positions, longer tours of duty, and different pay rates for the same job $[13,18,28,47,6]$ may impact on their mental health. Also related to depression is quality of social relationships [71]; and therefore lack of socialisation, recreation and friendships onboard $[1,26,39]$ may be expected to impact on the mental health of seafarers too.

\subsection{Research aims}

There is a call for more research exploring the psychosocial health and stress of seafarers $[14,18,38,51,58]$. Research and theory building is also urgently needed to support the efforts of the International Maritime Organisation (IMO) and International Labour Organisation (ILO), which set international maritime and labour standards, including the ILO's Maritime Labour Convention (MLC) ([36]; ITF, n.d.). Accordingly, the primary aim of this study was to explore perceptions and experiences of stress, resilience, and well-being amongst a sample of Filipino merchant seafarers. Investigating perceptions of stress, resilience and well-being amongst a sample of seafarers is required to inform organisational policies in the interest of optimal working and living conditions for maritime workers.

This research was undertaken in cooperation with a company known for its proactive approach to many of these challenges, having been the first recipient of the Global Healthy Workplace Award in 2013 [34]. One such psychosocial programme by this company was a pilot resilience-training programme, aiming to support the thriving of employees both on- and off-shore ([41,54]). This voluntary programme consisted of 12 resilience modules, incorporating elements of positive psychology, cognitive behavioural therapy, neuro-linguistic programming, and leadership training. Subsequent to piloting the programme at sea, the resilience programme was incorporated into a wider holistic health programme for seafarers in the company. The present study was used to also inform the development of this holistic health programme.

\section{Method}

\subsection{Participants and procedures}

Focus groups were conducted with merchant seafarers working in a large shipping organisation. Focus groups may optimally comprise between 6 and 12 participants [60]. For this study, focus groups included 
eight participants in each of four focus groups (all male) $(n=32)$. Purposeful sampling was used to recruit participants for focus groups. Attendees of the Shell ${ }^{1}$ International Ratings Conference held in Manila, Philippines, in December 2015 were invited to participate in focus group discussions - about their experiences as seafarers - as an event separate from the main conference meeting. English has been the lingua franca of the maritime industry for approximately the last century [62]. Focus groups were therefore conducted in English. All focus groups were audio-recorded, following the consent of participants. Ethical approval for this study was granted by the Health Policy \& Management/Centre for Global Health Research Ethics Committee, Trinity College Dublin, Ireland.

Participants were Filipino ratings across all departments (deck, engine and galley), and worked onboard liquefied natural gas carriers, product oil tankers and crude oil tankers, operating globally. To retain anonymity, we did not ask focus group participants for personally identifiable details, such as age. The categorisation of departments in merchant ships can be primarily classified as: (1) deck department, responsible for managing the navigation of the ship, and handling cargo operations and berthing instruments on the ship deck; (2) engine department, tasked with the operation and maintenance of the machinery of the ship; and (3) catering department, responsible for meal preparation and general housekeeping onboard [8]. Merchant seafarers are categorised as officers and ratings, and these groups are further divided by rank, ranging from captain to third officer, chief engineer to fourth engineer, and bosun to ordinary seaman [1].

\subsection{Study materials}

The primary researcher designed a 20 -item, semi-structured focus group schedule, which focused on perceptions and experiences of stress, resilience and well-being, underpinned by a review of the literature. The schedule also included a question in relation to the company's resilience programme and holistic health programme. A copy of the focus group schedule is provided in Appendix A. Several items explored perceptions and experiences of resilience and well-being from different perspectives, including the organisation, crew, and individual seafarer, reflecting a systems perspective of psychosocial aspects of maritime work [50].

For a number of items, a funnelling technique was used, whereby a general item was used before more specific probing items [35]. Probes were therefore used to deepen participants' answers to questions and increase the richness of the data [63]. For example, one item asked: "Do you have any personal experiences in relation to resilience or lack of resilience?" This was followed by two sub-items: "Do you have any positive experiences in relation to the resilience onboard the ships you are now working on or have worked on in the past?" and "Do you have any negative experiences in relation to the resilience onboard the ships you are now working on or have worked on in the past?"

The focus group schedule was first vetted with colleagues at the Centre for Global Health, Trinity College Dublin, to solicit feedback on the scope, clarity and flow of questions [64] and, where appropriate, the tool was refined. For example, the item "Do you have any personal experience in relation to resilience?" was rephrased as "Do you have any personal experience in relation to resilience or lack of resilience?" Context-specific vetting was then conducted by a Shell crewing manager based in Manila, Philippines, who assessed the focus group schedule in terms of the appropriateness of content and language for Filipino participants. This manager deemed the questions to be appropriate. Filipino participants were asked in the focus groups to also consider their own definitions and understanding of "resilience" and related constructs.

\footnotetext{
${ }^{1}$ The term "Shell" in this article refers to Shell International Trading and Shipping Company Limited (STASCo).
}

Piloting of the questions was conducted to refine the focus group schedule in relation to the framing and clarity of questions $[25,5,56,67]$. The primary researcher assessed the first focus group to evaluate the extent to which the focus group schedule was clear, understandable, capable of answering the research questions, and if any revisions were necessary $[22,33]$. As no significant refinement of the questions was deemed necessary, this pilot data was included as part of the formal data set of the study $[61,64]$. An internal pilot was therefore conducted as the first phase of the study, whereby data from the pilot phase contributed to the final analysis $[24,4]$.

\subsection{Data analysis}

The primary researcher transcribed verbatim all data in full from recordings of the focus groups. Preliminary perceptions and insights were written down as memos. Preliminary editing of the transcripts was performed whereby obvious redundancies and repetitions were removed from the data.

The technique of constant comparison analysis, as described by Elliott and Timulak [31], was used to analyse the data; accordingly, the data was distributed into meaning units - units by which the analysis was conducted. Meaning units are segments of the data that even if interpreted out of context would communicate adequate information to convey a piece of meaning to the reader [31].

Broad headings, or domains, for organising participants' responses were identified. These domains were structured broadly during the beginning research stages through the focus group schedule, but were further developed predominantly during data coding. Several organising frameworks were flexibly developed and tested until they were deemed to appropriately and parsimoniously fit the data.

The meaning units were coded, or categorised, within each domain. Such categories emerged from the meanings in the meaning units. Formulation of categories is an interpretive and interactive process whereby the researcher labels categories similarly to the actual language of participants, while also applying their own understanding and knowledge of previous theory and study findings [31].

\section{Results}

Domains and categories that emerged from data analyses are presented in Appendix B, and are illustrated schematically in Fig. 1. Domains and categories are not ordered in terms of importance nor do they imply any hierarchy. Ratings communicated their perceptions and experiences of stress, resilience and well-being in relation to 11 domains: workload; safety; social; support; salary; food; shore leave and signing off and on; nationality and culture; management; inequality; and optimisation. Within these domains, several categories were identified. For example, within the domain of "Nationality and Culture", ratings emphasised their preference for a mix of nationalities for officers onboard, and referred to cross-cultural misunderstandings onboard.

Two critical themes interlace the findings reported above, namely, recent changes in the working and living conditions of seafarers, and their preference for explicit organisational justice. The first, recent changes, was highlighted by participants in relation to the need for more socialisation and shore leave for example. The second, organisational justice, was emphasised by ratings in relation to, for example, the importance of an equal and fair work environment. Fig. 2 below presents the study's findings in relation to these two broader themes, illustrating how these themes both traverse several categories.

\section{Discussion}

The primary aim of this study was to explore perceptions and experiences of stress, resilience, and well-being amongst a sample of Filipino merchant seafarers. This discussion of the study's findings is not 

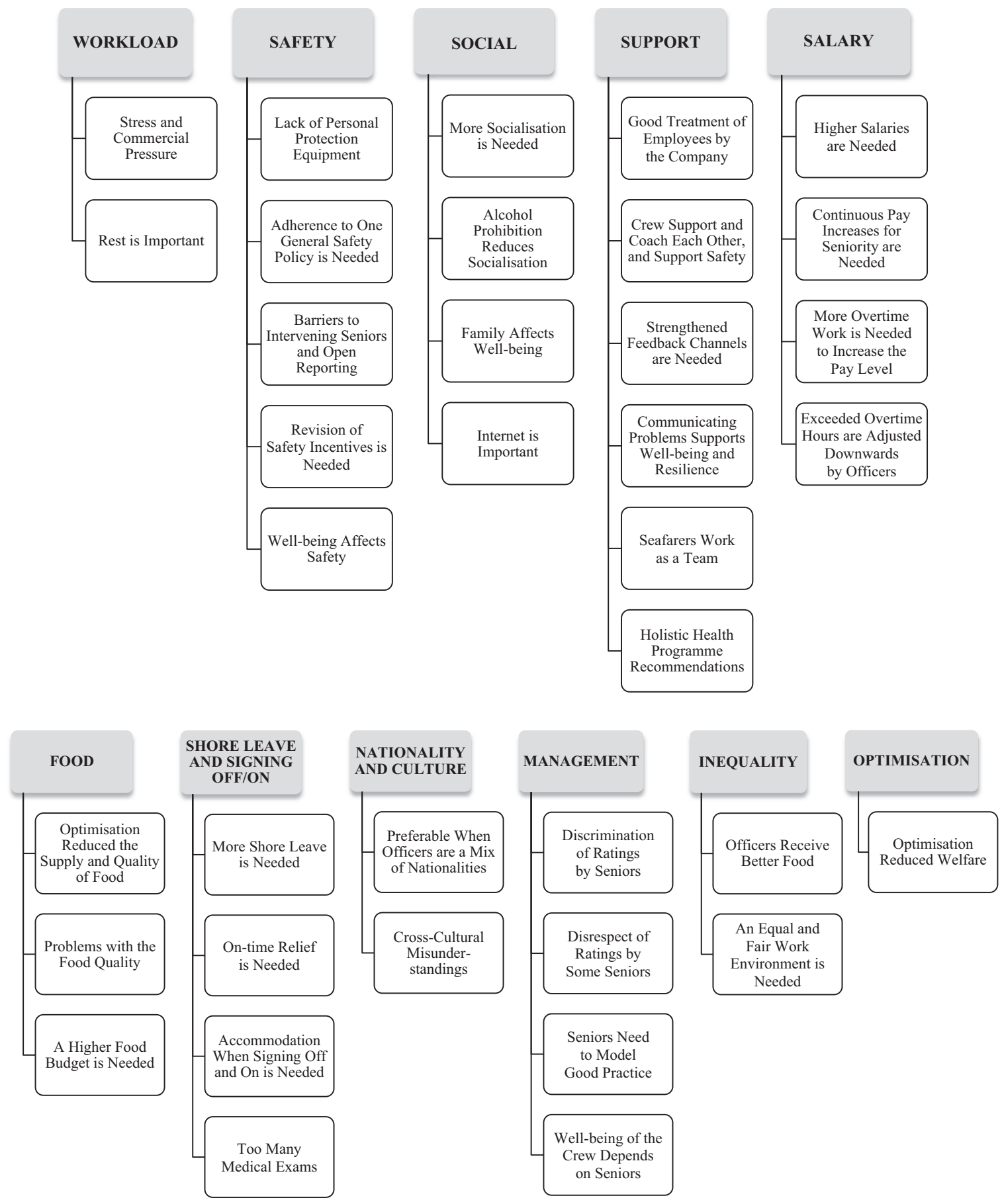

Fig. 1. Domains and categories for ratings.

intended to be either comprehensive or exhaustive, but to address some of the issues arising from the research in relation to the review of the literature.

\subsection{Recent changes}

Ratings reported experiencing stress, exemplified by a rating who asserted that "usually the number one problem with the seaman is stress, always". Participants' descriptions of stressors were complex and relative however, rather than absolute. For example, ratings indicated that cultural diversity onboard was a source of stress, whilst also expressing a preference for officers who were a mix of nationalities. Furthermore, ratings indicated the need for on-time relief, although several ratings indicated that some seafarers sought to extend their contracts depending on their financial stability for example.

In addition to reporting stress, participants described fewer opportunities to alleviate stress in recent years due to reduced socialisation and shore leave. These findings are reflective of the literature, which specifies a lack of socialisation and barriers to forming friendships onboard [1,26,72]. As emphasised by the ITF Seafarers' Trust [39] (p. 13) "increased support for onboard communities would increase coping mechanisms, emotional well-being, and social connectedness; as well as impacting on positive mental health outcomes". The literature similarly highlights a lack of shore leave $[21,43,44,58,68,76]$. It is noteworthy that the MLC, recognising the importance of this factor, states that "seafarers shall be granted shore leave to benefit their health and well- 
RECENT CHANGES

ORGANISATIONAL JUSTICE

BOTH THEMES
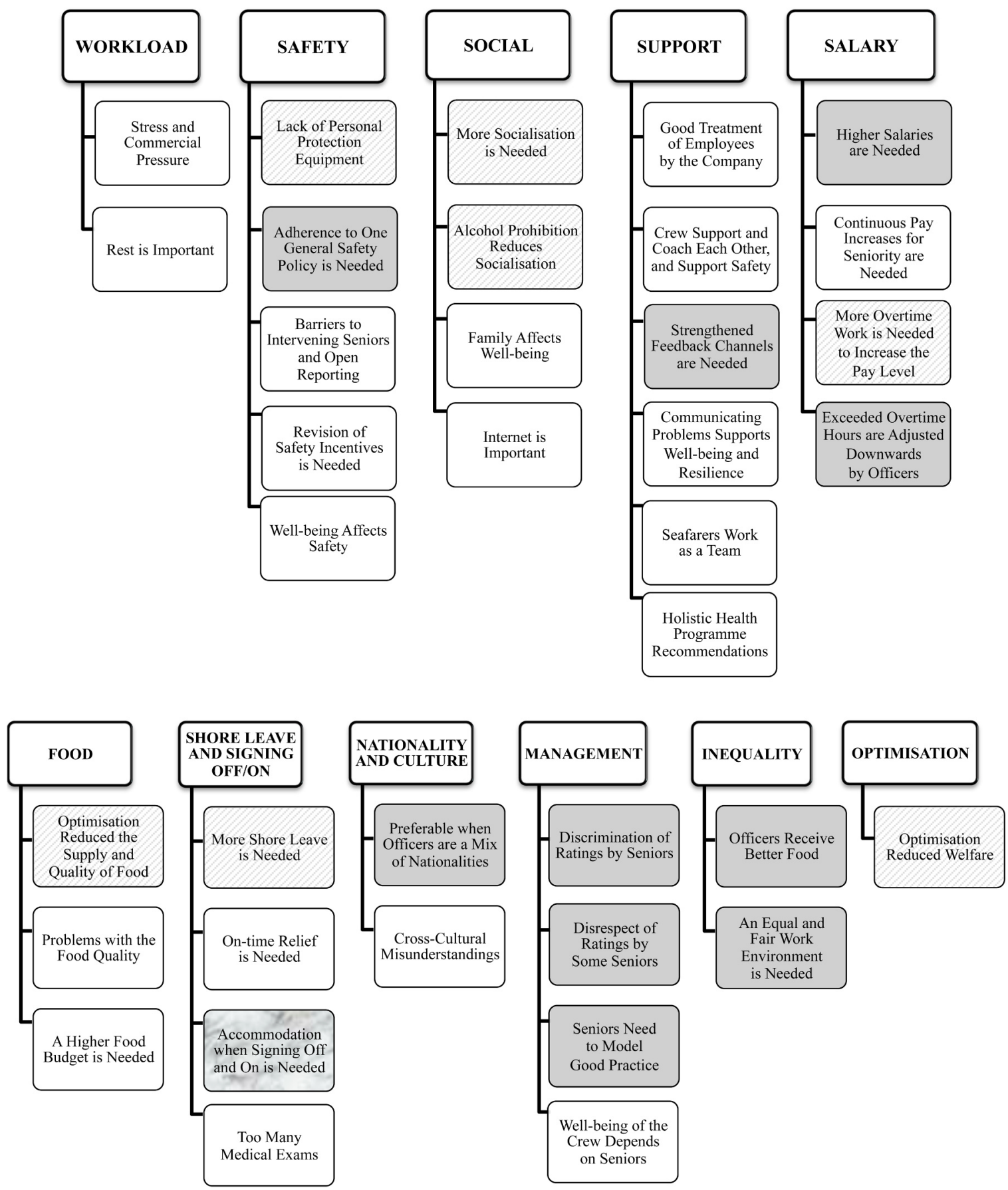

Fig. 2. Cross-cutting critical themes in relation to the study's findings.

being" (Regulation 2.4) ([36], p. 33).

Good treatment of employees by the company was also noted by ratings in relation to several factors including the promotion of a safe work environment and provision of Internet access. However, participants referred to recent cutbacks and changes in the organisation. The company's optimisation initiative (which reflects an industry-wide trend) underpinned many issues highlighted by ratings, which they asserted had resulted in cutbacks affecting personal protection equipment, socialisation, shore leave, hotel accommodation when signing off, and particularly the supply and quality of food. The 2016 Crewtoo Seafarers Happiness Index [27] similarly reported participants' concerns in relation to the provision of "good, healthy, tasty food", with 
some respondents of this study suggesting cuts to catering budgets. As noted, such economising by the company for which our participants worked is a microcosm of cutbacks across the maritime sector whereby the drive for profitability in the shipping industry has also led to decreased personnel onboard, longer working hours, and shorter turnaround schedules in ports [66]. As will be evident from many of the quotes above, it is not only the particular issue that is problematic for seafarers but also what it symbolises about themselves, and their value.

\subsection{Organisational justice}

Ratings highlighted the importance of an equal and fair work environment. Participants discussed several factors, referring for example to their perception of the provision of hotel accommodation to officers when signing off and on, and in particular the provision to officers of better food. Concerns expressed by ratings also included their perception of discrimination and disrespect by some officers; the adjustment downwards by officers of exceeded overtime hours; concealment of complaints and mistakes by officers (protecting others of the same nationality); enforcement of different rules by different senior officers; infringement of rules by captains; and the absence of upward appraisal of seniors by ratings. A number of these findings are also reported in the literature, including disrespectful treatment by officers of crew [74] and overtime hours worked onboard that are not recorded [69].

While several of these issues may well be contested by others in the shipping industry, perhaps the most important point is that they are nonetheless perceived as such. Several of these issues may be symbolic of injustice, with this feeling festering and causing more widespread discontent than necessary. For instance, a number of issues highlighted by ratings could be addressed through relatively simple and inexpensive modifications that would symbolise and signal a greater concern with equity, fairness and justice. For example, if officers and ratings already receive an equal food budget, a relatively inexpensive adaption would be to provide more equal food in terms of quality and choice for both officers and crew. Indeed, one rating recommended combining the officers' and ratings' mess rooms and serving a buffet. Similarly, upward appraisal of seniors by ratings, a relatively simple and low-cost initiative, could symbolise greater concerns with accountability, fairness and justice. Such simple, symbolic actions could powerfully signal to employees that they are valued [49].

Ratings highlighted the importance of equal remuneration for equal work. The MLC (Guideline B2.2.2) declares that "equal remuneration for work of equal value should apply to all seafarers employed on the same ship without discrimination based upon race, colour, sex, religion, political opinion, national extraction or social origin" ([36], p. 29). The provision to seafarers of different pay rates for the same job is perceived as discriminatory, inequitable and unfair $[18,28,9]$. Remuneration has a monetary value but also a symbolic value in organisations, and dual salaries generate a perception of organisational injustice, which leads to demotivation [17].

\subsection{Limitations}

Our participants are drawn from one event, organised by one company, for one cohort and for seafarers of one nationality. As this study did not comprise a large, representative sample, it is critical to caution against generalising from this study across the maritime sector, which constitutes an extensive scope of employers, flags, States, ship types, contract types, and recruitment and remuneration practices. Nonetheless, this is a group that globally constitutes a substantial number of seafarers who are rating, and which is greatly under-researched, particularly using qualitative methods that allow participants 'their own voice' in both constructing and responding to salient issues.

While confidentiality was assured, given that participation occurred in a work context, it is quite possible that participants were less frank than they would have been in another context. Indeed, respondents may have, either deliberately or unwittingly, provided socially desirable responses [70]. Given the high dependence of communities in LMICs on the income of seafarers [13], ratings may have been cautious of jeopardising their jobs by openly reporting their work experiences. However, participants appeared to be quite candid, providing both criticisms and praise, as evidenced above.

\subsection{Recommendations for future research}

As the seafaring workforce is isolated and dispersed, online or computer-based psychological interventions and training may be a valuable avenue of future research. A variety of Internet-based interventions have been developed and tested for common psychological disorders, and research indicates that these treatments frequently lead to similar outcomes as face-to-face psychotherapy, in addition to being cost-effective [3]. For example, online positive psychology interventions may be accessible, inexpensive, and scalable, with the capacity to reach a diversity of populations $[12,30,65]$. As recommended by Bergheim et al. [7], future research could focus on designing and fieldtesting a computer-based intervention to strengthen psychological capital and safety orientation in the maritime sector.

An equally important and interconnected area of inquiry is maritime health and well-being at the systems level. Importantly, factors that influence the well-being and performance of maritime workers are embedded in a variety of work levels, including the task, individual, team, organisation and industry [50]. Furthermore, maritime health is influenced by organisational, operational, environmental, safety and cultural factors, and a systems-based approach to research may enable integrated healthcare interventions [51]. While the MLC aspires to standards of good practices, the broader maritime industry is focused on 'rationalisation' of work practices; which is often not consistent with the spirit of the MLC, and may in certain cases contravene it. For companies to be competitive - even companies with a good reputation they may be pushed to rationalise in ways that undermine the wellbeing, self-respect and ultimately the performance of seafarers. It is therefore also time to reconsider what incentives at an industry level may best support the well-being of seafarers.

\section{Conclusion}

The confined setting of a ship presents particular opportunities to provide support programmes for seafarers to help them to reduce stress and to support their overall well-being while at sea [29]. However, as proposed by MacLachlan [47, p. 7], "no matter what sort of clever individual psychological interventions maritime psychologists can develop, implementing these in a fundamentally unfair and exploitative working environment can be counterproductive, individualising a systems problem". Psychosocial interventions that focus only at the individual level, while eschewing the broader work environment in which those individuals are expected to perform, may lead to further frustration and disengagement $[47,53]$. It is important that we address the organisational and industrial causes of perceived injustice, in addition to strengthening the capability of individuals to cope with difficult situations [48].

Changes in the work conditions of seafarers - such as uncertain employment prospects, reduced manning, and less enjoyable work environments - may reasonably be expected to impact on the psychosocial well-being of seafarers. Supporting the psychosocial well-being of seafarers may benefit both the individual seafarer and their employer, through improved well-being and job satisfaction and increased work performance, comprising a virtuous reinforcing cycle. Importantly, however, a supportive and just work environment is necessary to provide a good platform upon which individually focused psychosocial interventions can be usefully applied. The "silver wave of self-worth, duty and shipmates' welcome" is produced by seafarers, their companies and the broader industry in which they work - it constitutes a 
worthy and worthwhile investment for all.

Funding

One of the authors (JMV) received a Ph.D. scholarship from Shell International B.V. to conduct this research. The second author (MML) received no financial benefit for the research reported in this paper.

\section{Appendix A}

Focus Group Schedule for Ratings' Focus Groups

1. What do you understand by the term 'resilience'? What does this word mean to you? What do you feel it means in a psychological sense? What is resilience good for?

2. Do you have any personal experiences in relation to resilience or lack of resilience?

3. Do you have any positive experiences in relation to the resilience onboard the ships you are now working on or have worked on in the past?

4. Do you have any negative experiences in relation to the resilience onboard the ships you are now working on or have worked on in the past?

5. Have you any ideas or suggestions for how the company can strengthen the resilience of people working in the organisation?

6. Have you any ideas or suggestions for how the company can support the well-being more generally of people working in the organisation?

7. Have you any ideas or suggestions for how the company can strengthen the resilience of people working onboard ships?

8. Have you any ideas or suggestions for how the company can support the well-being more generally of people working onboard ships?

9. How do you see well-being from the perspective of the organisation?

10. How do you see well-being from the perspective of the ships' crew in general?

11. How do you see well-being from the perspective of individual seafarers?

12. How do you see yourself promoting well-being from the perspective of the organisation?

13. How do you see yourself promoting well-being from the perspective of the ships' crew in general?

14. How do you see yourself promoting well-being from the perspective of individual seafarers?

15. Do you believe that the experience and perceptions of health and well-being of people onboard impacts on the safety of ships? (If yes) how?

16. Are there events that have occurred in the past three months that have had an impact or influenced your thinking or understanding about your own resilience? (If yes) could you please expand on this?

17. What do you see or experience as the stressors or problems onboard for seafarers with regards to those that affect resilience or wellbeing?

18. How do you believe that the company can help to address or overcome these stressors or problems to help seafarers experience more resilience or well-being while onboard?

19. In January 2014, the Resilience Pilot (trial) Programme was introduced, which was provided to a number of ships to support seafarers' resilience and well-being. What are your opinions or ideas in relation to making the resilience programme available to all ships as part of a wider health programme? What would be good to include in this wider health programme?

20. Is there anything else that you would like to comment on in relation to resilience or well-being in the company context that you feel we have missed or not discussed? (If yes) could you please expand on this?

\section{Appendix B}

Findings: Domains and Categories that Emerged from Data Analyses

\section{Workload}

\subsection{Stress and commercial pressure}

Ratings indicated experiencing stress and commercial pressure. For example, one participant stated: "Usually the number one problem with the seaman is stress, always" (P8, FG3 [participant 8, focus group 3]). Ratings reported pressure to complete jobs quickly, as exemplified below:

(FG1) P3: Sometimes this happens from the officer, pressure ... You can finish this job this immediately time, like that, but for you it's not good because you know that it's unsafe, and time pressure.

P4: ... They said "easy, easy, but we need to finish".

P3: Yeah ... Yeah, not he wants easy but normal job.

Participants indicated that proper planning of jobs by management could alleviate pressure. For example, a rating specified: "Commercial and operational pressure ... We can avoid but through management when they are going to deal with planning the job or work before going on" (P6, FG2).

\subsection{Rest is important}

Ratings emphasised the importance of rest onboard. For example, a rating asserted that commercial pressure resulted in a shortage of rest:

(FG2) P6: ... Time pressure and commercial pressure ... of course the company will say "manage your time" [laugh], and if you are working for two days, you need to get rest for at least two days but nah the engine team galley won't let you rest for two days [participants laugh].

\section{P2: You rest on vacation!}

Notably, a number of ratings also indicated that rest hours were adequate:

(FG2) P4: ... They're restricting now the working hours and having more on resting hours ...

P7: It's OK. It's definitely OK.

P6: There's no issue in working hours.

\section{Safety}

\subsection{Lack of personal protection equipment}

The importance of personal protection equipment (PPE) was communicated by participants. As illustrated below, concerns were expressed in relation to the effect of the company's "optimisation" ${ }^{2}$ policy on PPE:

(FG1) P1: We have to have some for this optimisation because

\footnotetext{
${ }^{2}$ Optimisation may be defined as reviewing and redirecting organisational practices "towards achieving improvements in utilisation, efficiency and effectiveness" [45]. p. 12).
} 
sometimes on deck, you ask for PPE but sometimes they ignore because they said we have lack of this ...

P3: Sometimes you do not get whatever you like [laugh] ...

P1: Yeah sometimes they say that you have to use it again because we have lack of supply for that ... Gloves ...

P2: Spectacle ...

P8: Helmets are expired ... and use it again, even expired.

Notably, however, one rating commended the PPE: "It's much more better than the PPE of the other companies ... the quality ... all this good and nice PPE that we are using to keep us safe" (P4, FG3).

\subsection{Adherence to one general safety policy is needed}

Participants indicated that different senior officers enforced different rules, and expressed the need for adherence to one general safety policy. They also reported the need for captains to follow the rules, as demonstrated below:

(FG4) P5: ... Always said "this is my ship. Must be follow my rules" ... Different senior officer, different rules. Must be one rules to follow ...

P2: I think ma'am only fair because captain is following also the rules ...

P3: ... Already rules that we need to be (P8: follow), that we are guided. It is written in IMS (Integrated Management System). Just follow that rules and everybody will be happy (P8: Yeah) because other seniors they're doing their own rules ... if this captain want to smoke on bridge, they can do ...

P5: They can smoke.

\subsection{Barriers to intervening seniors and open reporting}

Ratings reported obstacles to intervening and open reporting. For example, a rating contended: "Most of the time it's happening that they're not accepting things that you're trying to tell them" (P4, FG2). While one rating asserted that open reporting was permitted, another rating stated that it was impeded:

(FG3) P3: ... This open reporting. You don't need to be afraid even if you are in the lowest rank ...

P8: ... If you will be always reporting and these senior officers will take the opportunity, they will retaliate, but I see that in other companies this is the most open when it comes to reporting but not all usually are doing this because they are not that resilient enough to do this because they are thinking lots of things about their jobs, about their families ... Sometimes we have difficult captains. They don't like to deal with problems, lots of problems, so it's not easy to report to him, but there are captains that are open ... Open reporting is there but on how to implement it is on the officers usually, on how resilient you are.

\subsection{Revision of safety incentives is needed}

Ratings indicated the need to amend safety incentives. Two participants indicated that safety incentives had changed due to optimisation and that safety incentives were now restricted:

(FG1) P8: ... 'Cause this optimisation, they discard that ... this safety incentive onboard ... Even before the safety ambassador has got safety dollars every month. They also discard that ... This is a new system ...
Researcher: So do you agree with this new system ...?

P4: I'm not so agree.

P1: Disagree ... because before every month we receive the phone card.

P8: Yeah ...

P1: Now they remove $\ldots$ because of this optimisation [participants laugh] ...

P8: ... They increase the standard ... That's why the phone card, it's hard to get now.

One rating recommended providing a monetary reward to all seafarers who finished their contract safely:

They give you that 30 dollars because that is your price because you are not getting hurt onboard. You can finish your contract well ... That's my suggestion ... so that's where we can improve safety. That is fair also. Everybody can receive it (P4, FG1).

\subsection{Well-being affects safety}

Ratings communicated the impact of their well-being on safety, as exemplified by one participant: "When you're already exhausted and tired, you don't care anymore if you are working safe or not [participants laugh]. You are only thinking that you need to finish your job" (P4, FG2). From the opposite perspective of well-being affecting safety, one participant indicated that too much concern for safety was affecting well-being:

Too concern of safety I think sometimes is affecting the well-being ... If you limit the [pause] shore leave, if you limit this alcohol, if you don't even give alcohol even for the certain amount of limit, this affect the well-being of the people because the socialisation is gone. The time to go to the shore leave, time to relax (P8, FG3).

\section{Social}

\subsection{More socialisation is needed}

Ratings expressed the need for more socialisation, and stated that social events had reduced due to optimisation:

(FG1) P8: In every month before we have a barbeque party ...

P2: It's social occasion ... but now no more, eh?

P8: But now, no, no. They cancel, optimisation [participants laugh] ... The social is good 'cause you can talk each other ...

P2: Singing ... Dancing.

P8: Yeah, yeah. You can (P2: relax) enjoy yourself ...

P2: Now no more.

P8: I experience one [laugh].

Researcher: One in how long?

P8: Six months ... Every month before ... Release your stress and not only work.

Ratings emphasised the importance of socialisation, as exemplified below:

It's really very important because these guys that you are mingling on, they are the ones going to be with you for almost six months of your contract, so I mean it's much more really easier ... when you are sharing your problems with them (P4, FG3).

Notably, one rating referred to expenditure by the company on 
socialisation: "You can see how much they are spending I mean for all these jubilations and this socialisation" (P4, FG3).

\subsection{Alcohol prohibition reduces socialisation}

Ratings emphasised a decline in socialisation due to the alcohol prohibition, as illustrated by one participant: "Ten years before, we have barbeque parties sometimes every Saturday or once a month, and then everyone gathers, of course alcohol then ... At the end of the night, we're happy" (P6, FG3). Ratings recommended re-authorising alcohol, with limits on the permitted quantity:

(FG3) P8: They can put limits ...

P4: As long as we are not above the limit of this alcohol policy, it's going to be OK.

One rating stated that safety precautions such as the alcohol prohibition infringed on well-being:

In other ships, they are still allowing this alcohol and some of these things, but because of safety procedures, safety precautions, I think they are not doing this anymore, and I heard sometimes in some captains that they are not allowing to bring people outside the port, surely because maybe they will be get drunk and they will be having an accident ... too concern of safety I think sometimes is affecting the well-being (P8, FG3).

\subsection{Family affects well-being}

Ratings highlighted the importance of family in relation to their well-being, as exemplified below:

In Philippines, we are, our culture is close-knit family ... our uncles, sometimes grandchildren are still living with us (P4: $\mathrm{Si}$ ), and all of these things, so we're a little close-knit family. What affects from the lower, from even the second cousin to the first cousin, it affects us (P8, FG3).

\subsection{Internet is important}

Ratings highlighted the importance of the Internet onboard. As illustrated by one participant, they emphasised the need for strengthened Internet to communicate with family: "Important is the communication from family ... but the problem is Internet" (P3, FG1). Contrastingly, several ratings praised the company regarding Internet access, as exemplified by a participant's observation in relation to communication with his family: "You don't have to worry about them and you're in constant communication (P4: Yeah). You worry more on your work" (P8, FG3).

\section{Support}

\subsection{Good treatment of employees by the company}

Ratings reported good treatment of employees by the company in relation to several factors. However, a particular focus on safety was evident when ratings discussed advantages of working in the company, as exemplified below:

They are treating us like we are family (P8: Yeah) so I think that's good enough for us. They don't want you to come onboard, sign your contract, come onboard and go home with one finger lost or something like that. They want you to come home as a whole (P1, FG4).

Participants also highlighted, for example, the provision of Internet by the company, as illustrated by one participant: "Also what's good ... the communication between you and your family" (P4, FG3). Medical evacuations and medical support by the company were also discussed by ratings. As asserted by a participant: "Even in medical evacuation ... they're really caring for their crew. It's a little bit much more better than the other companies" (P4, FG3).

\subsection{Crew support and coach each other, and support safety}

When asked how they promoted well-being, ratings reported supporting and coaching colleagues, and supporting safety. In relation to supporting colleagues, a rating for example communicated: "Sometimes when you are working together and one's under stress, you have to take care of him because you cannot force him to do the job" (P2, FG1). With regards to coaching colleagues, participants for example reported coaching new crew in relation to safety procedures. As asserted by a participant: "Creating a safety culture ... to intervene, to coach someone who is came from other company which the culture is different" (P3, FG3). In relation to supporting safety, a rating for example discussed intervening when colleagues were not working safely: "If I see my colleagues are doing unsafe behaviour, we do the intervention. That's why this is the way how to take care of our colleagues, of ourselves too" (P2, FG2).

\subsection{Strengthened feedback channels are needed}

Ratings called for strengthened feedback channels. One such issue highlighted by ratings was the need for upward evaluation of seniors by ratings, as exemplified in the excerpt below:

(FG3) P8: ... Crew are being evaluated every time we are going home, but I have never seen that crew are giving feedbacks to their superiors (P4: Superiors [nods]) ... Give us an empowerment that we can also evaluate our superiors ...

P2: ... So everybody will be equal ... We can give them also an evaluation.

Participants also highlighted issues in relation to reporting problems onboard. For example, two ratings indicated barriers to reporting problems about senior personnel:

(FG4) P1: ... You have problem with chief engineer, you can talk to the captain. However, if you have trouble with the captain, you can talk not only to the chief engineer but to the chief mate and to the chief engineer ...

P3: That's what the problem ... because captain and chief engineer has a good relationship.

P1: Yeah. That's one of the problem ...

P3: Because they have the same nationality.

These participants recommended that a third party collect ratings' feedback:

(FG4) P3: ... An example if this second officer or chief officer is a pain in the ass and they have a good relationship with the captain, this captain will hide only the problem (P8: Yeah) ... Third party will coming just to get our feedback.

P1: Yeah I agree ... I fully support on this idea ma'am.

Notably, two ratings indicated that there was an effective channelling system in the company in relation to reporting problems:

(FG4) P3: ... There's a proper channelling system ... If you will face some problem onboard, you know already where to report, who to report and what you're going to do.

P8: Going to do. Yeah, that's it [nods]. 


\subsection{Communicating problems supports well-being and resilience}

Ratings reported that well-being and resilience were strengthened when they communicated problems to colleagues and family. For example, as outlined below, ratings indicated that talking with colleagues and family supported their resilience:

(FG1) P6: ... You encounter some problems onboard, like you have to adjust you know [pause]. There's a lot of way how to adjust, counselling, like talking to your comrades and communicating with your family. That's all.

Researcher: $\mathrm{OK}$, and do you find that helps to be resilient onboard ...?

P8: Yeah ... Talking.

P6: It helps, yeah, a lot, yeah.

\subsection{Seafarers work as a team}

Participants contended that seafarers operated as a team. For example, one rating communicated: "We'll ask assistance from the different department. This is like teamwork, so we can cope the job" (P1, FG4). Another participant reported always feeling included in the ship management or team:

You feel also always [pause] included on the ship management or team from top to bottom 'cause nowadays every time you have a meeting, everyone is [laugh] included from bottom rank to going up, so you feel like you are always part of the ship ... 'cause every one of us are important. They are teaching us there but that is also what we feel (P6, FG2).

\subsection{Holistic health programme recommendations}

When asked to provide recommendations for the company's holistic health programme, ratings emphasised the importance of facilitating understanding of cultural differences, as illustrated below:

Cultural differences if there is some must be discussed so that it's easier for some new people who are going to ship to understand more the cultures of the people who you will be working with ... it will give you more, be more respectful to your colleagues and be more aware of them (P8, FG3).

Furthermore, ratings recommended a focus in the programme on improving people's attitudes onboard. One rating described a system on his ship of anonymously exchanging positive and negative feedback in relation to colleagues' attitudes:

(FG1) P8: For me, it's attitude, change bad to good ... 'cause the problem is the attitude ... So experience on my ship, so we are talking of that like everybody's attitude, we write in a paper and with no name ...

P2: Think it's a good idea ...

P8: ... We will change the paper and we will read, so now the first thing is the good and the second thing is this bad. Then the bad, we can suggest or we make an opinion how to change so to improve this attitude ... people onboard adjust their, you know, their attitude.

\section{Salary}

\subsection{Higher salaries are needed}

Ratings highlighted the need for higher salaries. For example, a rating asserted: "Your basic is very small" (P8, FG2). One rating highlighted different pay rates provided to different nationalities for the same work:

(FG4) P2: ... Some nationalities different salary, even we are same rank (P3: same job), same job, and their salary is more big than us ...

P8: Because I think that's because of the standard of living ... Because in U.K., the accommodations there is very high, you know, compared to Philippines.

P2: Not only U.K. we are compare. You see the Bruneian. Their salary is more big than us, than $\mathrm{AB}$, OS (able seaman, ordinary seaman). My salary is only compared to the salary of JOS (junior ordinary seaman) as an AB.

Ratings indicated the need for more frequent provision of new collective bargaining agreements (CBAs), as illustrated by one participant: "Our CBA does not continue on that ... Compared to the other company, every year they have a CBA" (P4, FG4). Ratings also asserted that standard pay was needed, as demonstrated by one comment:

Bruneian, Nigerian, they're receiving their salary for one year ... for us it's only for per contract, and we are asking this for quite some times that we can have the same, like when you are at home, you can also receive your basic salary (P1, FG4).

\subsection{Continuous pay increases for seniority are needed}

Ratings reported the need for continuous pay increases in accordance with seniority, as outlined below:

(FG4) P2: ... Here the seniority is stuck ...

P1: Yeah it's after ten years ... When you reach the maximum, it will stop there.

P2: Like other loyalty here ... like 15 years, 16 years, must be the loyalty and the seniority is then is continuous because in my last company is this good because the seniority is continuous every year, every year, every year, until you reach your retirement, 30 years, 40 years, your seniority will be high ...

P6: For me ma'am, I've been here for since (year). My seniority only 90 dollars.

\subsection{More overtime work is needed to increase the pay level}

Ratings conveyed the need for more overtime work, with an associated higher pay level. Several ratings indicated that overtime work had been reduced, as illustrated below:

(FG2) P7: ... We are more happy when we are getting overtime because that means more money, so the problem is you don't have the overtime anymore ...

P8: ... It's more your basic is very small and then no extra income.

Two ratings explained the reduction of overtime work as an outcome of stricter resting hours:

(FG2) P4: But I think it's reasonable because maritime organisation are now becoming more strict on resting period ...

P8: Yeah they have a reason ... At least ten ... ten hours working [laugh].

\subsection{Exceeded overtime hours are adjusted downwards by officers}

Ratings indicated that officers adjusted downwards the number of exceeded overtime hours that ratings worked, as illustrated below:

(FG1) P5: It's normally daily we have overtime, two hours a day, two hours to six hours ... and end of the month it's only exceeds five 
hours [laugh] ...

P4: ... Sometimes they can reduce 20 hours but you can work that 20 hours and then they can reduce ... supposed to be they can manage the time how to work so that's why the time is not exceeding the limit.

Ratings reported that they did not receive pay for exceeded overtime hours, as demonstrated in the excerpt below:

You are working but you are not paid ... Sometimes that's happen ... For example, you can reach 150 ... they can give 120 hours only for every month, and then they can cut the 30 hours. That is free. They cannot pay you any more ... because of the officers. They want to finish the job ... because they cannot manage how to make that job in proper time (P4, FG1).

\section{Food}

\subsection{Optimisation reduced the supply and quality of food}

Participants reported a reduction in the supply of food due to optimisation. For example, a rating asserted: "It's cutting the budget ... The supply are less of course" (P6, FG2). As outlined below, ratings indicated that optimisation had also affected the quality of food:

(FG3) Researcher: OK. Have you noticed a difference since optimisation in the quality of the food? ...

P2: Yeah it's really affected ...

P8: ... It's still 9, and every year inflation increase food. The cost of food increases, and they are still making this optimisation.

One rating contended: "The problem is that the people is suffering mostly for the food in terms of optimisation" (P4, FG2). Another rating criticised the impact of optimisation on food due to the importance of food onboard:

It needs to be improved from now on 'cause those foods on the ships now were really affected by their optimisation programme. Optimisation programme means they are cost cutting, so it's also affected the foods on the ship so I think that's the most important that optimisation programme should never be affecting the foods. In any cases yes, but not the food 'cause you know you need foods all the time (P2, FG3).

\subsection{Problems with the food quality}

Ratings specified problems with the quality of food. For example, participants indicated a lack of food diversity. As contended by a rating: "There is always food problems onboard ... there's some people who are going to complain, like it's always chicken every day" (P6, FG2). Two ratings indicated that there were barriers to issuing complaints about food:

(FG4) P3: ... If this chief cook is a pain in the ass, why you can't direct complain that to the captain? ...

P6: Yeah, they afraid you know? ...

P1: Ah but because of the relation of each other, that's one of the risks, one of the factors that we are not going forward ...

P3: And sometimes you need to become more honest. If your food is so shit, tell the chief cook "your food is shit, change it".

\subsection{A higher food budget is needed}

Ratings called for a higher food budget. For example, a participant indicated that the chief cook adhered to the captain's strict food budget, which restricted the food prepared by the second cook:

The captain is already like this on the budget [grips fist tightly] (P6: Yeah) ... from the captain like this already, the chief cook will do like this, so it will affect on the (P3: second cook) second cook, and although the chief cook will say to the rest of the crew that "ah no problem for me you know, so just on the second cook to do the menu or what he likes to cook". However, when the second cook ask for "can I have the salmon and the tuna for (P5: crew) the crew for lunch?", "oh now it's very expensive. You can please do the tilapia today, and tomorrow (P3: Yeah, yeah) it's tilapia again and make please on the next day" (P1, FG4).

\section{Shore leave and signing off and on}

\subsection{More shore leave is needed}

Ratings emphasised the need for more shore leave, as exemplified below:

They don't have definite terms on how to take the shore leave. This is sometimes very important on our well-being. It depends on the captain who is on the ship if he will give shore leave or not, or even if sometimes we are on anchorage for six or seven days and they will tell us that the port is very expensive ... In six months we have more longer contracts than these Europeans and Indian people, they have only three months, and sometimes we can only go outside for one or two times (P8, FG3).

Ratings reported a reduction of shore leave due to optimisation, as illustrated by a participant's comment: "To optimise, so we can save more money, we will not be giving you shore leave [laugh]" (P4, FG2). Notably, one rating indicated receiving shore leave: "In (country) ship, we have no problem with the food and this shore leaves because before we have two shore leaves" (P8, FG4).

\subsection{On-time relief is needed}

Ratings called for on-time relief. For example, two ratings alluded to conflict with seniors due to extended contracts, as demonstrated below:

With my captain, I'm already seven months onboard and my contract is only six, and he don't want me to send home and he want me to extend for one month. I said "if you will not send me on this port, I will call the DPA (Designated Person Ashore), I will call the ITF (International Transport Workers' Federation)" (P3, FG4).

Furthermore, participants contended that officers, unlike ratings, could sign off in any port, asserting for example: "In some port, they said "Expensive. You cannot sign off there. When you go back, go another. That is the cheap ticket. You will sign off there", but the officer, everywhere [speaking loudly], everywhere they sign off" (P2, FG4). Notably, however, several ratings indicated that some seafarers sought to extend their contracts:

(FG3) P8: ... This is a little contradiction because I noted the fact that I saw a lot of people who are trying to extend their contracts.

P6: Yeah if you have somebody who are sending their children to school, expenses are too high ...

P8: How financially stable you are.

\subsection{Accommodation when signing off and on is needed}

Ratings called for accommodation when signing off and on vessels. In relation to signing off, they asserted that prior to optimisation, hotel accommodation was provided for crew before their flights home; however, crew now stayed onboard before travelling home. They 
indicated that during this time, when all rooms were occupied, they shared a one-bed cabin with their reliever, as illustrated by one participant's comment:

Once the reliever came, we can go and sign off and stay in the hotel, but now since they are trying to control this optimisation thing, you have to stay onboard until it's OK. Maybe a few hours before your flight, you can go directly to the airport, and then most of the time you have to stay in your cabin with your reliever in one room. You have only one bed ... Usually you have a sofa on the other side of the cabin ... when all the rooms are occupied ... or you can stay on the crew bar (P4, FG2).

Participants also called for hotel accommodation before signing on, as follows:

(FG4) P1: ... Philippines to Europe, it's a long haul, and with all the jetlag and tiredness of the people, I think they put you in hotel at least one night for you to rest because it's no good that you are flying 20 hours, 18 hours, and you go direct to your ship ...

P6: And then straight to work.

Participants indicated that only officers stayed in hotels when signing off and on:

(FG4) P3: What was happen usually, if ratings sign off, we go direct to the airport, and if we join on the ship, we go direct on the ship (P8: Yeah), but usually officer before they join and before they leave the ship, they stay in the hotel ...

P6: That's unfair ma'am.

\subsection{Too many medical exams}

Participants asserted that they undertook a medical exam, including an X-ray, for each contract every six months. One rating specified that a follow-up X-ray would be performed when a health issue was identified, which could result in up to four X-rays per year. Participants expressed concern in relation to the health implications of this number of X-rays, as indicated below:

(FG1) P1: Adjustment for medicals because some other nationalities, their medical's two years expiration. Ours, every other contract, we go general medical ... Every six months ...

P8: It's not good. For example, this X-ray ... It's not good for health ... Twice a year.

Unidentified participant: Once you are not pass, you can X-ray again, so it will three to four times a year ...

P3: But in the medical certificate, there is two years expiry, but maybe they get medical every contract they have, ah?

\section{Nationality and culture}

\subsection{Preferable when officers are a mix of nationalities}

Participants expressed their preference for a mix of nationalities for officers onboard. They referred to concealment of complaints and mistakes by officers of the same nationality, as illustrated below:

Much better if this four senior came from different nationalities than one nationality. Example, these four seniors are all Indian, what will happen if there's some mistake, they will only cover up (P8: Yeah), but if mixed nationality, example this Indian make mistake, this Croatian will not allow it to be covered up (P3, FG4).

Two ratings indicated that the leadership was respectful and discrimination was lessened when officers were a mix of nationalities, as illustrated by a participant's observation: "If mixing the nationalities, the benefits will be you will treat you nice I believe or the discrimination will be lessened (P8: lessened), but if you put all the Croatian there, all you can see is cursing" (P1, FG4).

\subsection{Cross-cultural misunderstandings}

Ratings referred to cross-cultural misunderstandings, including cultural misunderstandings between crew and supervisors:

(FG3) P8: ... Because of their culture, you are having difficulties communicating with them, and you don't know that they are already angry at you so this affects your well-being because sometimes he is your superior ... Have you been ma'am with these Greek people? ... when they are planning party, they will throw glasses (P4: throw glasses [laugh]), throw lots of plates and you will be thinking they are angry or maybe it will cut my little fingers ... but this is their culture ... I have one mastman that he want to go because of this ... He's afraid [participants laugh].

P4: ... Sometimes we Filipinos can take that as a challenge or a dare ... It's really important that we understand cultures.

One participant highlighted the importance of social gatherings for understanding other cultures:

Some people talk very loud, like Nigerians ... Filipinos get annoyed when we hear those very loud voices and so sometimes it creates a division ... It is important that we have these gatherings once in a while so that we will understand each other's culture (P6, FG3).

\section{Management}

\subsection{Discrimination of ratings by seniors}

Ratings reported experiencing discrimination by seniors. For example, one rating referred to discrimination by European officers:

Discrimination ... Asian people like us or the ratings who can be easily replaced are afraid to speak on this ... European nationalities that sometimes we are working until wee hours and they have their party and all something and they making breaks of one hour or one and a half hour and if they see us making a break for 15 or 20 minutes they will shout at you and they will make problems at you, so sometimes we are not resilient enough to counter this so it affects also our job because our morale become low ... You have to think of the future how, of the next trip or the next, and usually we will say "this too shall pass" ... I don't think in this fleets but in others companies, this usually happens. Europeans, they take lots of breaks (P8, FG3)

Similarly, one participant referred to racial discrimination onboard: "Discrimination ... any kind of company ... racists is there, always" (P2, FG4).

\subsection{Disrespect of ratings by some seniors}

Ratings reported disrespectful behaviour by some seniors. As expressed by a rating: "Some, just for example of the captain, if you can intervene, 'no I'm the captain' ... so you are in low rank ... we don't have any respect" (P4, FG1). One rating indicated that some captains were kind, while others were disrespectful:

When you are on the bridge, you are happy because you are going to see captain which is very kind and "oh how are you today?", not like "hey clean this. Why are you just standing here? Go clean" [laugh] (P6, FG2).

Participants indicated that some officers viewed themselves as 
superior, asserting for example: "Some of them is, they you know like a senior, like they said senior or like a king onboard" (P2, FG4).

\subsection{Seniors need to model good practice}

The need for seniors to model good practice was emphasised by ratings. For example, participants asserted that compliance with rules by ratings was dependent on compliance by seniors, as follows:

(FG2) P6: If your, what do you call that, leaders are not following the orders, of course the ratings will follow what the leaders are doing, so be a good example so then [laugh].

P5: That is good words: Be a good leader ... so the followers will follow all the rules.

\subsection{Well-being of the crew depends on seniors}

Ratings indicated that their well-being was dependent upon seniors. For example, one participant specified that the welfare of the crew depended on seniors in terms of stress:

(FG4) P3: Actually ma'am, ship's crew welfare depends on the captain or senior officer onboard (P8: Yeah). If they are a good person, ship will become no pressure, less stress, because it depends on the senior officer that we are working ...

P1: ... I fully agree with that one.

\section{Inequality}

\subsection{Officers receive better food}

As illustrated below, participants communicated that the same food budget was provided for both officers and crew, but officers received better food:

(FG1) P8: ... His treatment is not fairly to the officer and the crew. You know, the officer he prepare very good food, and the crew he prepare not good ...

P3: ... It's same budget everyone, but the problem is not same this food.

Participants stated that officers chose from a selection of food, while all ratings received the same food, as exemplified below:

Crew is always a Filipino, officer is a mix, so for the officer, chief cook give this special menu. For the Filipino, same food because for the Filipino preparing from second cook. Chief cook is for officer ... chief cook will give the special for the officer and second cook only for the Filipino food so that is the problem (P3, FG1).

One participant suggested that cooks were pressured to give food to officers due to evaluations: "As chief cook ... we are very pressured to give food to the officers because usually they are the one who are giving us the evaluations" (P8, FG3). Another participant recommended serving a buffet so that officers and ratings ate the same food:

(FG4) P3: ... Buffet food much better, so everybody will enjoy same food.

P1: Ah that's much even better, yeah.

Notably, a rating stated that there was no problem with food in his fleet: "In our fleet ... we have no problem with the food ... We make our own menu Filipino, menu we submit to the chief cook" (P8, FG4).

\subsection{An equal and fair work environment is needed}

Participants highlighted the importance of an equal and fair work environment. For example, ratings specified that the officers' bar was good while the crew's bar was empty:

(FG4) P2: ... Why they treated us different, the officers different, the ratings different? ... Discrimination is there, always ... The alleyway said no discrimination ... but I don't believe that because when you see when you onboard, you have the crew bar and the officer bar. It's not the same. Officer side is good ... Crew side (P3: empty), nothing $\cdots$

P8: Yeah.

Moreover, as previously outlined, participants indicated that different privileges were provided to officers than to crew in relation to signing off and on, as demonstrated by a participant's remark: "Ratings sign off, we go direct to the airport, and if we join on the ship, we go direct on the ship, but usually officer before they join and before they leave the ship, they stay in the hotel" (P3, FG4).

Indeed, as previously indicated, the importance of a fair work environment was expressed by several ratings. For example, a rating alluded to fairness regarding the need for adherence by captains to rules: "Only fair because captain is following also the rules" (P2, FG4). Furthermore, participants highlighted unfair working conditions in relation to officers receiving better food, asserting for example: "Many of the chief cook ... they didn't treat us fairly" (P2, FG1).

\section{Optimisation}

\subsection{Optimisation reduced welfare}

As illustrated by the findings reported above, ratings indicated that optimisation had impacted on several factors including personal protection equipment, socialisation, shore leave, hotel accommodation when signing off, and primarily food. Ratings summarised this impact by suggesting that a number of areas had been affected, as illustrated by a participant's observation: "Really once you cut the cost for everything, there will be, for example, impact on everything, shore leave, for the recreation and everything" (P7, FG2). One participant declared that cutbacks were causing suffering for the crew:

You're cutting some of their leisures, you're cutting some of their supplies, you're cutting off some of their food just to save money. Of course, the company is built to save money, to earn money. We understand that but at least to be considerable about it because some captain are a little bit more on saving money, even though some of these crew are already suffering (P4, FG2).

\section{References}

[1] T. Alderton, M. Bloor, E. Kahveci, T. Lane, H. Sampson, M. Thomas, et al., The Global Seafarer: Living and Working Conditions in a Globalized Industry, International Labour Office, Geneva, Switzerland, 2004.

[2] P. Allen, E. Wadsworth, A. Smith, The prevention and management of seafarers fatigue: a review, Int. Marit. Health 58 (2007) 167-177.

[3] G. Andersson, N. Titov, Advantages and limitations of Internet-based interventions for common mental disorders, World Psychiatry 13 (2014) 4-11, https://doi.org/ 10.1002/wps.20083.

[4] M. Arain, M.J. Campbell, C.L. Cooper, G.A. Lancaster, What is a pilot or feasibility study? A review of current practice and editorial policy, BMC Med. Res. Methodol. 10 (2010) 1-7, https://doi.org/10.1186/1471-2288-10-67.

[5] H. Arksey, P. Knight, Interviewing for Social Scientists: An Introductory Resource with Examples, SAGE, London, United Kingdom, 1999.

[6] A.M. Baylon, E.M.R. Santos, Attractions, problems, challenges, issues and coping strategies of the seafaring career: MAAP seafarers perspectives, in: A. Weintrit, T. Neumann (Eds.), Safety of Marine Transport: Marine Navigation and Safety of Sea Transportation, CRC Press, Leiden, The Netherlands, 2015, pp. 21-30.

[7] K. Bergheim, M.B. Nielsen, K. Mearns, J. Eid, The relationship between psychological capital, job satisfaction, and safety perceptions in the maritime industry, Saf. Sci. 74 (2015) 27-36, https://doi.org/10.1016/j.ssci.2014.11.024.

[8] S. Bhattacharjee. A Guide to Merchant Navy Officer Ranks, 2017. Available at: 〈http://www.marineinsight.com/careers-2/a-guide-to-merchant-navy-officerranks/> (Accessed 9 October 2017). 
[9] Y. Bhattacharya, Employee engagement as a predictor of seafarer retention: a study among Indian officers, Asian J. Shipp. Logist. 31 (2015) 295-318.

[10] BIMCO (Baltic and International Maritime Council), and International Chamber of Shipping. Manpower Report: The Global Supply and Demand for Seafarers in 2015 (Executive Summary). BIMCO, International Chamber of Shipping, 2015. Available at: 〈http://www.ics-shipping.org/docs/default-source/resources/safety-securityand-operations/manpower-report-2015-executive-summary.pdf?Sfvrsn =16〉 (Accessed 9 October 2017).

[11] M. Bloor, An essay on 'health capital' and the Faustian bargains struck by workers in the globalised shipping industry, Sociol. Health Illn. 33 (2011) 973-986, https:// doi.org/10.1111/j.1467-9566.2011.01347.x.

[12] L. Bolier, C. Majo, F. Smit, G.J. Westerhof, M. Haverman, J.A. Walburg, et al., Costeffectiveness of online positive psychology: randomized controlled trial, J. Posit. Psychol. 9 (2014) 460-471, https://doi.org/10.1080/17439760.2014.910829.

[13] M. Borovnik, Occupational health and safety of merchant seafarers from Kiribati and Tuvalu, Asia. Pac. Viewp. 52 (2011) 333-346, https://doi.org/10.1111/j.14678373.2011.01459.x.

[14] A. Carotenuto, A.M. Fasanaro, I. Molino, F. Sibilio, A. Saturnino, E. Traini, et al., The Psychological General Well-Being Index (PGWBI) for assessing stress of seafarers on board merchant ships, Int. Marit. Health 64 (2013) 215-220, https://doi. org/10.5603/IMH.2013.0007.

[15] S.C. Carr, Global mobility, local economy: it's work psychology, stupid!, in: S.C. Carr (Ed.), The Psychology of Global Mobility, Springer, New York, NY, 2010, pp. $125-150$.

[16] S.C. Carr, Anti-Poverty Psychology, Springer, New York, NY, 2013.

[17] S.C. Carr, M. MacLachlan, Humanitarian work psychology, Psychologist 27 (2014) $160-163$

[18] T. Carter, Working at sea and psychosocial health problems: report of an International Maritime Health Association Workshop, Travel. Med. Infect. Dis. 3 (2005) 61-65, https://doi.org/10.1016/j.tmaid.2004.09.005.

[19] T. Carter, Mapping the knowledge base for maritime health: 3 illness and injury in seafarers, Int. Marit. Health 62 (2011) 224-235.

[20] T. Carter, Merchant Seamen's Health, 1860-1960: Medicine, Technology, Shipowners and the State in Britain, The Boydell Press, Woodbridge, United Kingdom, 2014

[21] H. Clare, Down to the Sea in Ships: Of Ageless Oceans and Modern Men, Vintage, London, United Kingdom, 2015.

[22] H. Collins, Creative Research: The Theory and Practice of Research for the Creative Industries, AVA Publishing, Lausanne, Switzerland, 2010.

[23] P. Conroy, M. Mahon, M. Doyle, S. Reddin, E. Byrne, Out of Sight - Out of Mind: Supporting Hard-to-Reach Groups to Participate in Decisions that Affect Their Lives, Combat Poverty Agency, Dublin, Ireland, 2008 (Available at), 〈http://www. combatpoverty.ie/publications/OutOfSightOutOfMind_2008.pdf $\rangle$ (Accessed 9 October 2017).

[24] C. Cooper, A. O'Cathain, D. Hind, J. Adamson, J. Lawton, W. Baird, Conducting qualitative research within Clinical Trials Units: avoiding potential pitfalls, Contemp. Clin. Trials 38 (2014) 338-343, https://doi.org/10.1016/j.cct.2014.06. 002.

[25] J.W. Creswell, C.N. Poth, Qualitative Inquiry and Research Design: Choosing Among Five Approaches, 4th ed, SAGE, Thousand Oaks, CA, 2017.

[26] Crewtoo. Crewtoo Seafarers Happiness Index, 2015. Available at: 〈http://survey. crewtoo.com/happiness $>$ (Accessed 9 October 2017).

[27] Crewtoo (2016). Crewtoo Seafarers Happiness Index (Quarter 4). Available at: $\langle$ http://crewtoo.s3〉. amazonaws.com/wp-content/uploads/2016/02/Seafarer Happiness Index_Q4.pdf [accessed October 9, 2017].

[28] D.N. Dimitrova, Seafarers' rights in the globalized maritime industry, in: R. Blanpain (Ed.), Alphen aan den Rijn, Kluwer Law International, The Netherlands, 2010.

[29] N. Doyle, M. MacLachlan, A. Fraser, R. Stilz, K. Lismont, H. Cox, et al., Resilience and well-being amongst seafarers: cross-sectional study of crew across 51 ships, Int. Arch. Occup. Environ. Health 89 (2016) 199-209, https://doi.org/10.1007/ s00420-015-1063-9.

[30] F. Drozd, L. Mork, B. Nielsen, S. Raeder, C.A. Bjørkli, Better days - a randomized controlled trial of an internet-based positive psychology intervention, J. Posit. Psychol. 9 (2014) 377-388, https://doi.org/10.1080/17439760.2014.910822.

[31] R. Elliott, L. Timulak, Descriptive and interpretive approaches to qualitative re search, in: J. Miles, P. Gilbert (Eds.), A Handbook of Research Methods for Clinical and Health Psychology, Oxford University Press, (New York, NY), 2005, pp. 147-160.

[32] A. Furnham, Justice at work, in: S.C. Carr, M. MacLachlan, A. Furnham (Eds.), Humanitarian Work Psychology, Palgrave Macmillan, Basingstoke, United Kingdom, 2012, pp. 52-79.

[33] P. Gill, K. Stewart, E. Treasure, B. Chadwick, Methods of data collection in qualitative research: interviews and focus groups, Br. Dent. J. 204 (2008) 291-295, https://doi.org/10.1038/bdj.2008.192.

[34] Global Centre for Healthy Workplaces. London Press Release 2013: Alexandra Health, Toyal America and Royal Dutch Shell Named Winners in Search for Healthiest Workplaces, 12th April 2013, 2013. Available at: 〈http://www. globalhealthyworkplace.org/PR-London-Awards-and-Summit-2013.html (Accessed 9 October 2017)

[35] R.M. Grinnell, Y.A. Unrau, Social Work Research and Evaluation: Foundations of Evidence-based Practice, 9th ed, Oxford University Press, New York, NY, 2010.

[36] ILO (International Labour Organization). Maritime Labour Convention, 2006, as Amended. Geneva, Switzerland: ILO, 2006. Available at: 〈http://ilo.org/wcmsp5/ groups/public/_ed_norm/_normes/documents/normativeinstrument/wcms 554767.pdf> (Accessed 9 October 2017).
[37] ITF (International Transport Workers' Federation), Out of Sight, Out of Mind: Seafarers, Fishers and Human Rights, ITF, London, United Kingdom, 2006.

[38] ITF (International Transport Workers' Federation). (n.d.). IMO and ILO. Available at: 〈http://www.itfseafarers.org/ITI-IMO-ILO.cfm〉 (Accessed 9 October 2017)

[39] ITF Seafarers' Trust. Summary Report from the ITF Seafarers' Trust Autumn 2016 Workshop on Social Isolation, Depression and Suicide (SIDS). London, United Kingdom: ITF Seafarers' Trust, 2017. Available at: 〈http://www.seafarerstrust.org/ programmes-2/publications/ $>$ (Accessed 9 October 2017).

[40] R.T.B. Iversen, The mental health of seafarers, Int. Marit. Health 63 (2012) 78-89.

[41] K. Jacobs. Focus on 'Resilience' to Improve Wellbeing, Says Shell's Health Chief. Dinton, United Kingdom: HR Magazine (MA Business and Leisure), 2013. Available at: 〈http://www.hrmagazine.co.uk/article-details/focus-on-resilience-to-improvewellbeing-says-shells-health-chief (Accessed 9 October 2017).

[42] M. Jeżewska, I. Leszczyńska, B. Jaremin, Work-related stress at sea self estimation by maritime students and officers, Int. Marit. Health 57 (2006) 66-75.

[43] E. Kahveci, Port Based Welfare Services for Seafarers: Summary Report, ITF Seafarers' Trust, London, United Kingdom, 2007 (Available at), 〈http://www. itfseafarers.org/files/seealsodocs/4423/WelfareReportl.pdf〉 (Accessed 9 October 2017).

[44] R. Kantharia. 12 Main Reasons Seafarers Quit Sea Jobs, 2017. Available at: 〈http:/ www.marineinsight.com/life-at-sea/12-main-reasons-seafarers-quit-sea-jobs/〉 (Accessed 9 October 2017).

[45] S. Khare, Optimizing the Organization: Unleashing the Potential of Practices, Processes and People, Tata McGraw-Hill, New Delhi, India, 2006.

[46] M. Lipowski, M. Lipowska, A. Peplińska, M. Jeżewska, Personality determinants of health behaviours of merchant navy officers, Int. Marit. Health 65 (2014) 158-165, https://doi.org/10.5603/imh.2014.0030.

[47] M. MacLachlan, Maritime psychology: definition, scope and conceptualization, in: M. MacLachlan (Ed.), Maritime Psychology: Research in Organizational and Health Behavior at Sea, Springer, Cham, Switzerland, 2017, pp. 1-18.

[48] M. MacLachlan, Still too POSH to push for structural change? The need for a macropsychology perspective, Ind. Organ. Psychol. 10 (2017) 403-407, https://doi. org/10.1017/iop.2017.36.

[49] M. MacLachlan, S.C. Carr, E. McAuliffe, The Aid Triangle: Recognizing the Human Dynamics of Dominance, Justice and Identity, Zed, New York, NY, 2010.

[50] M. MacLachlan, S. Cromie, P. Liston, B. Kavanagh, A. Kay. Psychosocial and organisational aspects, In Textbook of Maritime Medicine (2nd ed.), ed. T. Carter (Bergen, Norway: Norwegian Centre for Maritime Medicine), 2013. Available at: $\langle$ http://textbook.ncmm.no/〉 (Accessed 9 October 2017).

[51] M. MacLachlan, B. Kavanagh, A. Kay, Maritime health: a review with suggestions for research, Int. Marit. Health 63 (2012) 1-6.

[52] M. McVeigh. A Silver Wave: A Collection of Poetry by Michael W. McVeigh, 2017. Available at: 〈https://jmcveigh0. wixsite.com/michaelwmcveigh〉 (Accessed 9 October 2017)

[53] J. McVeigh, M. MacLachlan, B. Kavanagh, The positive psychology of maritime health, J. Inst. Remote Health Care 7 (2016) 20-28.

[54] J. McVeigh, M. MacLachlan, R. Stilz, H. Cox, N. Doyle, A. Fraser, et al., Positive psychology and well-being at sea, in: M. MacLachlan (Ed.), Maritime Psychology: Research in Organizational and Health Behaviour at Sea, Springer, Cham, Switzerland, 2017, pp. 19-48.

[55] A. Mellbye, T. Carter, Seafarers' depression and suicide, Int. Marit. Health 68 (2017) 108-114, https://doi.org/10.5603/IMH.2017.0020.

[56] G.A. Morgan, N.L. Leech, G.W. Gloeckner, K.C. Barrett, IBM SPSS for Introductory Statistics: Use and Interpretation, 4th ed, Routledge, New York, NY, 2011.

[57] R. Ndjaboué, C. Brisson, M. Vézina, Organisational justice and mental health: a systematic review of prospective studies, Occup. Environ. Med. 69 (2012) 694-700, https://doi.org/10.1136/oemed-2011-100524.

[58] M. Oldenburg, H.J. Jensen, Merchant seafaring: a changing and hazardous occupation, Occup. Environ. Med. 69 (2012) 685-688, https://doi.org/10.1136/oemed2011-100619.

[59] M. Oldenburg, H.J. Jensen, U. Latza, X. Baur, Seafaring stressors aboard merchan and passenger ships, Int. J. Public Health 54 (2009) 96-105, https://doi.org/10. 1007/s00038-009-7067-z.

[60] A.J. Onwuegbuzie, W.B. Dickinson, N.L. Leech, A.G. Zoran, A qualitative framework for collecting and analyzing data in focus group research, Int. J. Qual. Methods 8 (2009) 1-21, https://doi.org/10.1177/160940690900800301.

[61] D. Plowright, Using Mixed Methods: Frameworks for an Integrated Methodology, SAGE, London, United Kingdom, 2011.

[62] B. Pritchard, Some lexical aspects of translating specialised texts, In Insights into Specialized Translation (Volume 46 of Linguistic Insights: Studies in Language and Communication), eds M. Gotti and S. Sarcevic (Bern, Switzerland: Lang), 261-288, 2006.

[63] M. Quinn Patton, How to Use Qualitative Methods in Evaluation, Sage, Newbury Park, CA, 1987

[64] S.M. Ravitch, N. Mittenfelner Carl, Qualitative Research: Bridging the Conceptual, Theoretical and Methodological, SAGE, Thousand Oaks, CA, 2016.

[65] N.M. Redzic, K. Taylor, V. Chang, M. Trockel, A. Shorter, C.B. Taylor, An Internetbased positive psychology program: strategies to improve effectiveness and engagement, J. Posit. Psychol. 9 (2014) 494-501, https://doi.org/10.1080/ 17439760.2014 .936966

[66] L.W. Rydstedt, M. Lundh, An ocean of stress? The relationship between psychosocial workload and mental strain among engine officers in the Swedish merchant fleet, Int. Marit. Health 61 (2010) 168-175.

[67] H. Sampson, Navigating the waves: the usefulness of a pilot in qualitative research, Qual. Res. 4 (2004) 383-402, https://doi.org/10.1177/1468794104047236.

[68] Shoretoo. Shoretoo: Connecting You to Crew, 2015. Available at: 〈https://crewtoo. 
s3). amazonaws.com/wp-content/uploads/2015/09/Shoretoo-Newsletter-2.pdf (Accessed 9 October 2017).Crewtoo. Shoretoo: Connecting you to Crew (Issue 02), 2015. Available at: https://crewtoo.s3.amazonaws.com/wp-content/uploads/ 2015/09/Shoretoo-Newsletter-2.pdf (Accessed 26 October 2018).

[69] A. Slišković, Occupational stress in seafaring, in: M. MacLachlan (Ed.), Maritime Psychology: Research in Organizational and Health Behavior at Sea, Springer, Cham, Switzerland, 2017, pp. 99-126.

[70] P.E. Spector, Social desirability bias, in The SAGE Encyclopedia of Social Science Research Methods (Vol. 1), eds M. S. Lewis-Beck, A. Bryman, and T. Futing Liao (Thousand Oaks, CA: SAGE), 1044-1045, 2004.

[71] A.R. Teo, H. Choi, M. Valenstein, Social relationships and depression: ten-year follow-up from a nationally representative study, PLoS ONE 8 (2013) e62396, https://doi.org/10.1371/journal.pone.0062396.

[72] M. Thomas, Lost at Sea and Lost at Home: The Predicament of Seafaring Families, Seafarers International Research Centre, Cardiff, United Kingdom, 2003.

[73] UNCTAD (United Nations Conference on Trade and Development). Review of maritime transport. Geneva, Switzerland: UNCTAD. Available at: 〈http://unctad.
org/en/PublicationsLibrary/rmt2017_en.pdf).

[74] United States Coast Guard. Investigation into the Explosion and Sinking of the Chemical Tanker Bow Mariner in the Atlantic ocean on February 28, 2004, with Loss of Life and Pollution. Washington, DC: United States Coast Guard, 2005. Available at: 〈https://www.uscg.mil/hq/cg5/cg545/docs/documents/bowmar1. pdf> (Accessed 9 October 2017).

[75] A. Velankar, Mental Health and Wellbeing of a Seafarer, Thome Group, Singapore, 2017 (Available at), 〈http://www.thome.com.sg/mental-health-and-wellbeing-ofa-seafarer $/>$.

[76] D. Walters, N. Bailey, Lives in Peril: Profit or Safety in the Global Maritime Industry? Palgrave Macmillan, New York, NY, 2013

[77] War on Want, and ITF (International Transport Workers' Federation). Sweatships, 2002. Available at: 〈http://www.waronwant.org/resources/sweatships〉 (Accessed 9 October 2017).

[78] WHO (World Health Organization). (n.d.). Mental Health: Suicide Data. Available at: 〈http://www.who.int/mental health/prevention/suicide/suicideprevent/en/〉 [accessed October 9, 2017]. 